opposition to nuclear power-namely, the Swedish election and the Californian referendum-competing claims on restricted public expenditure and the energy research and development budget, rising capital costs, greater environmental safeguards, and downturns in traditionally exponential electricity growth rates, proponents of nuclear power are facing a major reassessment of its future role.

In conclusion, Commoner is a persuasive commentator and despite

\section{Energy supply and demand}

\section{Peter Chapman}

Potential Energy: An Analysis of World Energy Technology. By Michael Kenward. Pp. $x+227$. (Cambridge University: Cambridge, London and New York, September 1976.) Hardcover $£ 6.20$; papercover $£ 2.80$.

ENERGY research and development is one of the few fields of inquiry that enjoys a steady growth in its level of financing, perhaps more so in the USA than in the UK. Over the past two and a half years Mike Kenward has charted the ups and downs, the fashions and flops in energy research and development in the bi-weekly 'Energy File' in New Scientist. He has now put together a large part of this material in Potential Energy which claims to be an "analysis of world energy technology". The review of energy supply options is certainly comprehensive, from solar to nuclear fusion through oil, coal, gas, fission, wind and waves. For anyone not familiar with the range of developments in these fields this book is certainly a useful starting point, but only a starting point.

There are two major defects in this book. The first is that Kenward studiously avoids trying to assess the relative merits and disadvantages of the energy technologies discussed. Occasionally we catch a glimpse of what the author's opinions are: "as far as nuclear research and development goes it is doubtful if even more spending is justified". But by and large he merely describes the technology and describes other people's reactions to the problems. This journalistic style was appropriate for a magazine feature on energy, but leaves the reader of the book in a policy vacuum. This is characterised by the platitudinous and obvious conclusion to the book which points to the twin dangers of "putting all our eggs in one basket only to discover there is a hole in the bottom" his strong environmentalist bias and support for solar energy, agrees that the so-called energy gap will not be "swept away in a flood of sunlight". One minor complaint: for a book which is inevitably quantitative, there are no tables or charts to ease the exposition.

John Chesshire is a Fellow of the Science Policy Research Unit, University of Sussex, UK.

and spreading research and development funds "so widely that no energy technology receives enough support to prove itself". Since this was, and remains, the obvious problem in formulating an energy research and development policy it seems a shame that nowhere does Kenward address himself to the problem.

A more glaring defect in Kenward's treatment of energy research and development policy is the other half of the energy question, namely energy demand. In 218 pages of text there are no more than 8 pages on factors likely to influence energy demand. This reflects the institutional blindspot to the one energy research and development area likely to pay off most handsomely in the medium term. It seems likely that with a moderate range of incentives UK energy demand could be con- strained to increase by less than $30 \%$ over the next 25 years (compared with an increase of $60 \%$ over the past 25 years). If this potential exists with present energy utilisation technology it is likely that further research and development on energy utilisation technologies could lead to even greater savings. The known savings are cheaper by a factor of between three and ten, in both capital and total cost terms, than the equivalent increases in energy supplies. This indicates that there is considerable scope for developing additional energy-saving technologies before they cost as much as the energy supply technologies. This is recognised in some of the small print in Walter Marshall's discussion document Energy $R \& D$ in the $U K$ (Department of Energy, Series of Papers on Energy, June 1976), but is ignored in practice. It seems that Kenward has been unduly influenced by the massive volume of literature and finance associated with energy supply technology and has missed perhaps the largest 'potential energy' area in an otherwise useful review.

Peter Chapman is a Senior Lecturer in the Department of Physics, and Director of the Energy Research Group at the Open University, Milton Keynes, $U K$.

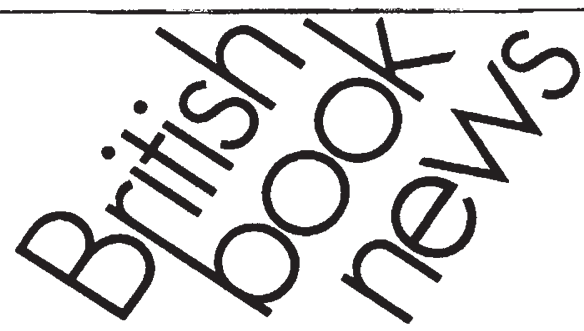

offers the scientist and technologist a unique guide to new books

each month: over 100 new books and new editions in pure and applied science reviewed by specialists

list of 200 forthcoming books in the sciences

survey articles of recent literature in all subjects

Bulletins Editor Dept. Scientific \& Industrial Research, Wellington, N.Z.

Choice (American Library Assoc.) Librarian, Nottingham
I know of no other source of high quality concise reviews over such a wide subject range'

'Can be enthusiastically recommended'

'the most useful single British reviewing periodical' . . 